\title{
Economic Evaluation of Yield-Increasing Wheat Seeds Using a Distance Function Approach
}

\section{Philipp Wree, Johannes Sauer, and Stefan Wimmer}

\begin{abstract}
New wheat-breeding techniques, such as hybridization and genetic modification, show increasing yield potential. This study involves estimating multi-output multi-input production technology by stochastic frontier techniques to evaluate the economic value of this yield potential. An input-oriented distance function is formulated and applied to European Farm Accountancy Data of 23 European countries. Based on the analysis, an average shadow value is derived for the increase in the marginal yield of wheat that corresponded to $18.87 € /$ ha. Further, technical change, technical efficiency, and returns to scale are measured for different European regions.
\end{abstract}

Key Words: shadow value, stochastic distance frontier, wheat production

JEL classification: Q12, Q18, D24

\section{Introduction}

Innovations in agricultural crop production contribute to food safety and food security and affect the environment. Recent innovations in plant breeding are often based on hybrid and genetic modification (GM) breeding strategies. These techniques are widespread in the global production of several cash crops such as corn, soybeans, rapeseeds, rice, and barley but not in the production of wheat. Simultaneously, the increase in wheat yield lags behind. For example, the annual average yield increase in rapeseeds in Europe from 1994 to 2014 corresponds to 3.6 percent, and it was more than double the yearly increase for wheat (1.6 percent) (FAOSTAT 2016). However, wheat is one of the most important crops for global food security (Shiferaw et al. 2013), and breeding innovations are crucial for keeping up with the increasing global demand. In addition to social relevance in terms of food security, wheat is also the most dominant crop for European farmers. Wheat is cultivated on approximately 26 percent of the 100.3 million ha of arable land in the EU-28 (FAOSTAT 2016). Former studies indicated that wheat yield could be significantly increased by

Philipp Wree and Stefan Wimmer are researchers at the Department of Agricultural Production and Resource Economics at the Technical University of Munich. Johannes Sauer is a professor at the Department of Agricultural Production and Resource Economics at the Technical University of Munich. Correspondence: Philipp Wree - Department of Agricultural Production and Resource Economics - Technical University of Munich, Alte Akademie 12 - 85350 Freising - Germany • Phone: +498161 71-5151, Email: philipp.wree@tum.de

Agricultural and Resource Economics Review 47/3 (December 2018) 610-633

(C) The Author(s) 2018. This is an Open Access article, distributed under the terms of the Creative

Commons Attribution licence (http://creativecommons.org/licenses/by/4.0/), which permits unrestricted re-use, distribution, and reproduction in any medium, provided the original work is 
innovative breeding strategies. Based on GM technology, researchers developed a wheat variety (HOSUT) with a yield-increasing potential of 28 percent compared to its conventional counterpart (Saalbach et al. 2014). Longin et al. (2013) evaluated different hybrids and conventional wheat varieties and observed that hybrids were superior in terms of yield by 10.7 percent on average. Despite their potential, GM wheat varieties are not commercially produced due to social and political reasons, and wheat hybrid areas increase only gradually.

In this study, we first apply stochastic frontier analysis and construct multi-output multi-input distance functions (DFs) to represent output-input relationships for European crop production technology. The estimated function provides empirical applications for measuring farm efficiency and productivity (Zhou, Zhou, and Fan 2014) and accounted for complementarity and supplementarity of inputs (Sauer and Wossink 2013). Multi-output functions are beneficial because it is not necessary to distinguish as to which fraction of an input is used to produce a specific output. This type of detailed production information is often not available, as in the case of the European Farm Accountancy Data (FADN) used in this study. Further, using DFs has an advantage because it does not require price data or explicit behavioral assumptions (Kumbhakar, Wang, and Horncastle 2015, 27). Second, based on the estimates for the multi-output multi-input production technology, a potential price is proposed in terms of a marginal shadow value (MSV) that farmers would be prepared to pay for yield-increasing wheat seed material. The MSV measures the economically justified costs for seeds that marginally increase yields or output in wheat production under the assumption of optimal input combination.

DFs constitute an established methodology to examine various agricultural production patterns. Studies including Brümmer, Glauben, and Thijssen (2002), Key and Sneeringer (2014), Newman and Matthews (2006), Reinhard, Lovell, and Thijssen (1999), Tsionas, Kumbhakar, and Malikov (2015), and Sauer and Latacz-Lohmann (2015) applied this methodology to analyze the European and American dairy farming sectors with respect to aspects such as technical efficiency and technical change. Other extant studies, such as Coelli and Fleming (2004), Fleming and Lien (2009), Paul and Nehring (2005), and Rahman (2009), studied farms' diversification strategies. Solís, Bravo-Ureta, and Quiroga (2009) and Sauer and Wossink (2013) used this concept to analyze relationships between agricultural output and ecosystem services management of farms. Shadow prices derived from such agricultural DFs were mostly used to determine and value unwanted environmental damages (Hailu and Veeman 2001, Färe, Grosskopf, and Weber 2006, Arandia and Aldanondo-Ochoa 2011, Njuki and Bravo-Ureta 2015). In contrast to these studies, the present study examines the shadow price of a yield-increasing innovation as a desirable outcome. To the best of our knowledge, no study to date has used DFs to construct a shadow price for such an (desirable) innovation. Previous studies, including Zilberman et al. (2015), Brookes and Barfoot (2014), and Qaim (2009), which examined the economic benefits of breeding innovations, did not account for different production technologies and the substitutability of inputs. 
The remainder of this paper is structured as follows. Section 2 introduces the theoretic model. Section 3 outlines the methodology used to construct DFs and measure marginal shadow values. In Section 4, data and estimation procedures are described. Empirical results are presented in Section 5. The paper concludes with a summary and discussion of the main empirical findings and outlines the implications of the results.

\section{Conceptual Framework}

Production theory is the basis of the estimation of a stochastic frontier and inputoutput relationships in the present study. It is assumed that farms are offered a certain technology set that describes the relationship between inputs and outputs. The farmer can allocate inputs to generate outputs within the technology. Some inputs, such as land, could be exogenous in the short run, while others are endogenous. We assume that the farmer can choose inputs to optimize a cost-minimization objective function. Eventually optimizing behavior makes all input and output choices endogenous (Kumbhakar, Asche, and Tveteras 2013). Endogenous decision variables imply the possibility of farms with inefficient production, which could then be measured by the DF approach. Furthermore, the setting of multioutput multi-input DFs allows to account for marginal interactive and substitutional relationships between inputs and outputs through elasticities. Elasticities are estimated with respect to each input and output. A marginal shadow value for wheat seeds is derived through an economic evaluation of the marginal effects between the input (seed) and the output (wheat). This value is then used to evaluate the economic impact of marginal yield-increasing wheat seeds, which constitutes the main aim of the study. The MSV differs from market price because it evaluates the importance of the innovation within the production technology in monetary units while considering substitutional input relationships. Yield-increasing seeds are viewed as an embodied innovation, thereby implying that it is under the farmer's control to introduce the innovation and potentially extend her/his seed expenditures. The MSV indicates the maximum price premium for marginal yield-increasing seed innovations paid by the average farmer.

In the model used in the study, input markets are seen as perfectly competitive. This implies that the size of a single farm relative to the size of the market is so small such that the farm has no influence on input prices.

This section involves the introduction of the theoretical framework of the DF upon which we base our marginal shadow value calculation. The production technology set at time $t,\left(S^{t}\right)$ represents an input vector $x^{t}=\left(x_{1}^{t}, \ldots, x_{N}^{t}\right) \in R_{+}^{N}$ that produces an output vector $y^{t}=\left(y_{1}^{t}, \ldots, y_{M}^{t}\right) \in R_{+}^{M}$, which is formally expressed as follows:

$$
S^{t}=\left\{\left(x^{t}, y^{t}\right): x^{t} \text { can produce } y^{t}\right\}
$$

(Newman and Matthews 2006). 
$S^{t}$ denotes all feasible input-output vectors, and all inputs are assumed as freely disposable.

We apply an input-oriented DF, developed by Shephard (1970), to represent multi-output and multi-input technologies. Given a technically feasible set $\left(S^{t}\right)$, the input-oriented DF measures for each observation the largest radial contraction of an input vector $\left(x^{t}\right)$, given outputs $\left(y^{t}\right)$ (Färe and Primont 1995). The mathematical representation of the optimization function is as follows:

$$
\left.D_{\mathrm{I}}^{t}\left(x^{t}, y^{t}\right)=\max _{\rho}\left\{\rho>0:\left(x^{t} / \rho\right) \in S^{t}\right)\right\} .
$$

This functional form measures the maximum scalar (denote as $\rho$ ), such that $x^{t} / \rho$ remains in the feasible production technology set. The DF assumes values lesser than or equal to 1 . That is $D_{\mathrm{I}}^{t}\left(x^{t}, y^{t}\right) \leq 1$ if $x^{t} \in S^{t}$.

The DF value for a given observation corresponds to 1 if and only if the observation is part of the frontier of the production technology set $S^{t}$. Values between 0 and 1 indicate production with a distance to the production frontier and, thus, technical inefficiency (Coelli and Fleming 2004). Increasing efficiency of a farm corresponds to a larger $\rho$ value, which implies that the farm is closer to the stochastic frontier. By definition $D_{\mathrm{I}}^{t}\left(x^{t}, y^{t}\right)$ is a non-decreasing, positively linearly homogenous and concave in $x^{t}$ and nonincreasing in $y^{t}$ (Coelli and Fleming 2004, Sauer, Frohberg, and Hockmann 2006).

\section{Multi-output Multi-input Stochastic Input-distance Function Approach}

For the analysis in the study, an input-oriented DF was selected as we focus on marginal input effects. We estimate a multi-output multi-input distance DF in a flexible translog form, allowing for all possible input-output interactions and including dummy variables for year (denoted as $(Y)$ ), country (denoted as $(C))$ and economic size (denoted as $(E)$ ):

$$
\begin{aligned}
\ln D_{\mathrm{I}}^{t}(x, y, t)= & \alpha_{0}+\sum_{m=1}^{M} \beta_{m} \ln y_{m}^{t}+\frac{1}{2} \sum_{m=1}^{M} \sum_{n=1}^{N} \beta_{m n} \ln y_{m}^{t} \ln y_{n}^{t}+\sum_{k=1}^{K} \alpha_{k} \ln x_{k}^{t} \\
& +\frac{1}{2} \sum_{k=1}^{K} \sum_{l=1}^{L} \alpha_{k l} \ln x_{k}^{t} \ln x_{l}^{t}+\sum_{k=1}^{K} \sum_{m=1}^{M} \delta_{k m} \ln x_{k}^{t} \ln y_{m}^{t} \\
& +\omega_{0} t+\frac{1}{2} \omega_{00} t^{2}+\sum_{m=1}^{M} \zeta_{m t} \ln y_{m}^{t} t+\sum_{k=1}^{K} \eta_{k t} \ln x_{k}^{t} t \\
& +\sum_{p=1}^{P} \vartheta_{p} Y_{p}+\sum_{q=1}^{Q} \mathrm{l}_{q} C_{q}+\sum_{r=1}^{R} \kappa_{r} E_{r}
\end{aligned}
$$


$D_{\mathrm{I}}^{t}$ denotes the measured input distance function (IDF), where $y$ and $x$ correspond to vectors of outputs and inputs, respectively. The subscripts $m$ and $n$ denote farm output, and the subscripts $k$ and $l$ denote farm inputs. All inputs and outputs include a time trend $(t)$. Furthermore, $\alpha, \beta, \delta, \omega, \zeta, \eta, \vartheta$, l, and $\kappa$ denote parameters to be estimated.

An input variable (in this case, seeds, as denoted by $x_{1}^{t}$ ) is used to normalize the stochastic IDF. This imposes linear homogeneity with respect to the inputs $\left(\sum_{k=1}^{K} a_{k}=1\right)$ (Coelli and Perelman 1999). Additionally, for symmetry purposes the restriction $\alpha_{k l}=\alpha_{l k},(k, l=1,2, \ldots, L)$ and $\beta_{m n}=\beta_{n m}(m, n=1,2$, ..., $M$ ) is fulfilled (Coelli and Perelman 1999). Therefore, the DF can be rewritten to enable its econometric estimation as follows:

$$
\begin{aligned}
\ln \left(\frac{D_{\mathrm{I}}^{t}}{x_{1}^{t}}\right)= & \alpha_{0}+\sum_{m=1}^{M} \beta_{m} \ln y_{m}^{t}+\frac{1}{2} \sum_{m=1}^{M} \sum_{n=1}^{N} \beta_{m n} \ln y_{m}^{t} \ln y_{n}^{t}+\sum_{k=2}^{K} \alpha_{k} \ln \left(\frac{x_{k}^{t}}{x_{1}^{t}}\right) \\
& +\frac{1}{2} \sum_{k=2}^{K} \sum_{l=2}^{L} \alpha_{k l} \ln \left(\frac{x_{k}^{t}}{x_{1}^{t}}\right) \ln \left(\frac{x_{l}^{t}}{x_{1}^{t}}\right)+\sum_{k=2}^{K} \sum_{m=1}^{M} \delta_{k m} \ln \left(\frac{x_{k}^{t}}{x_{1}^{t}}\right) \ln y_{m}^{t} \\
& +\omega_{0} t+\frac{1}{2} \omega_{00} t^{2}+\sum_{m=1}^{M} \zeta_{m t} \ln y_{m}^{t} t+\sum_{k=2}^{K} \eta_{k t} \ln \left(\frac{x_{k}^{t}}{x_{1}^{t}}\right) t \\
& +\sum_{p=1}^{P} \vartheta_{p} Y_{p}+\sum_{q=1}^{Q} \mathrm{I}_{q} C+\sum_{r=1}^{R} \kappa_{r} E_{r}=\mathrm{TL}\left(y_{m}^{t},\left(\frac{x_{k}^{t}}{x_{1}^{t}}\right), t\right) \\
& +\sum_{p=1}^{P} \vartheta_{p} Y_{p}+\sum_{q=1}^{Q} \mathrm{\iota}_{q} C_{q}+\sum_{r=1}^{R} \kappa_{r} E_{r}
\end{aligned}
$$

where TL denotes translog. The equation can be rearranged as follows:

$$
\begin{aligned}
& \ln D_{\mathrm{I}}^{t}-\ln x_{1}^{t}=\operatorname{TL}\left(y_{m}^{t},\left(\frac{x_{k}^{t}}{x_{1}^{t}}\right), t\right)+\sum_{p=1}^{P} \vartheta_{p} Y_{p}+\sum_{q=1}^{Q} \mathrm{l}_{q} C_{q}+\sum_{r=1}^{R} \kappa_{r} E_{r} \\
& -\ln x_{1}^{t}=\operatorname{TL}\left(y_{m}^{t},\left(\frac{x_{k}^{t}}{x_{1}^{t}}\right), t\right)+\sum_{p=1}^{P} \vartheta_{p} Y_{p}+\sum_{q=1}^{Q} \mathrm{l}_{q} C_{q}+\sum_{R=1}^{R} \kappa_{r} E_{r}-\ln D_{I}^{t}
\end{aligned}
$$

By setting $-\ln D_{0 i}^{t}=-u_{i}^{t}$ and including a symmetric error $\left(v_{i}^{t}\right)$ that reflects random factors such as measurement errors, stochastic shocks, or unobserved inputs, the stochastic input DF (Coelli and Perelman 1996) is obtained as follows: 


$$
-\ln x_{1}^{t}=\operatorname{TL}\left(y_{m}^{t},\left(\frac{x_{k}^{t}}{x_{1}^{t}}\right), t\right)+\sum_{p=1}^{P} \vartheta_{p} Y_{p}+\sum_{q=1}^{Q} \mathrm{l}_{q} C_{q}+\sum_{r=1}^{R} \kappa_{r} E_{r}-u^{t}+v^{t}
$$

where $v_{i}^{t}$ denotes a random error term, which is assumed to be independent and identically distributed (i.i.d.) with $N\left(0, \sigma_{v}^{2}\right)$ and independent of $u_{i}^{t}$, and intended to capture events beyond the farmer's control. The term $u_{i}$ corresponds to a nonnegative random error term, which is assumed to be i.i.d. with $N\left(\mu, \sigma_{u}^{2}\right)$ and to follow the specification $u_{i}^{t}=u_{i} \exp (-\eta(t-T))$, that is intended to capture time-varying technical inefficiency effects in inputs (Battese and Coelli 1992).

The first-order partial derivatives of equation 7 measure the partial elasticities for inputs $x_{k}\left(\varepsilon_{x_{1}, x_{k}}\right)$ and the partial elasticity for outputs $y_{m}\left(\varepsilon_{x_{1} y_{m}}\right)$ relative to $x_{1}$. The value for $\varepsilon_{x_{1}, y_{m}}\left(-\varepsilon_{D^{1}, y_{m}}=-\frac{\partial \ln D_{i}}{\partial \ln y_{m}}=\frac{\partial \ln x_{1}}{\partial \ln y_{m}}=\varepsilon_{x_{1}, y_{m}}\right)$ estimates the required percentage change in $x_{1}$ from a 1 percent change in $y_{m}$, holding all output ratios constant (Paul and Nehring 2005). The mean of the negative sums of the partial elasticities of $y_{m}\left(\varepsilon_{x_{1}, y_{m}}\right)$ represents scale economies at the sample mean $\left(\mathrm{SE}=-\sum_{m=1}^{M} \varepsilon_{x_{1}, y_{m}}\right)$ (Paul and Nehring 2005). Thus, it reflects the extent to which overall input use must increase to support a 1 percent increase in all outputs by holding all input ratios constant. The elasticities of inputs $\left(\varepsilon_{x_{1}, x_{k}}\right)$ contain information on the slope of the production possibility frontier and represent the output contribution of $x_{k}$ relative to $x_{1}$.

Further, for each subsample, technical change (TC), as the first-order partial derivative with respect to time $(t)$ and technical efficiency (TE), are determined for each subsample. Given this, it is possible to differentiate various European production systems. The individual technical efficiency for the $i$ th firm is then estimated as follows:

$$
\mathrm{TE}_{i}(u, x, t)=\exp \left(-u_{i}\right)=\frac{x_{i}^{t}}{x_{i}^{t^{*}}}
$$

where $\mathrm{TE}_{i}$ measures the deviation of particular observations from the estimated frontier (Paul and Nehring 2005).

\section{Marginal Shadow Value}

The estimation of shadow prices is based upon the IDF's dual relationship with the cost function (Färe and Primont 2006). The partial elasticities, as mentioned previously, contain information on marginal products (MP) which are used to derive MSVs. In this study we are interested in the marginal shadow value for seeds as wheat output increases. Thus, we predominantly focus on the partial elasticity relationship $\varepsilon_{x_{1} y_{m}}$ with $x_{1}=x_{\text {seeds }}$ and $y_{m}=y_{\text {wheat }}$ : 
(9)

$$
\varepsilon_{x_{1}, y_{m}}=\frac{\partial \ln x_{1}}{\partial \ln y_{m}}
$$

From the partial elasticity for output (or 'input share' of $y_{m}$ [relative to $x_{1}$ ]) $\varepsilon_{x_{1} y_{m}}$, we can calculate the marginal product $\left(\partial x_{1} / \partial y_{m}\right)$ of $y_{m}$ on $x_{1}$, as follows:

$$
\varepsilon_{x_{1}, y_{m}}=\frac{\partial \ln x_{1}}{\partial \ln y_{m}}=\frac{\partial x_{1}}{\partial y_{m}} \frac{y_{m}}{x_{1}}
$$

$$
\mathrm{MP}_{x_{1} y_{m}}=\frac{\partial x_{1}}{\partial y_{m}}=\frac{\varepsilon_{x_{1}, y_{m}}{ }^{*} x_{1}}{y_{m}}
$$

In order to derive the MSV per ha, $\mathrm{MP}_{x_{1} \cdot y_{m}}$ is multiplied with the average total expenditures on seeds/ha $\left(E_{\text {seeds }} * \mathrm{ha}^{-1}\right)$ as given below:

$$
\operatorname{MSV}_{X_{\text {seeds }} \cdot y_{m}}=\operatorname{MP}_{X_{\text {seeds }} . y_{m}}\left(E_{\text {seeds }}{ }^{*} \text { ha }^{-1}\right) .
$$

With respect to the model structure, the study follows Kumbhakar, Wang, and Horncastle (2015), assuming a half-normal distribution of the inefficiency term $\left(u^{t}\right)$. Estimates of the parameters for the above-outlined model were obtained using maximum likelihood procedures based on a STATA 13 routine.

\section{Data and Estimation}

Annual FADN data with 302,041 observations in 23 European countries (Belgium (BEL), Czech Republic (CZE), Denmark (DEN), Germany (DEU), Greece (ELL), Spain (ESP), Estonia (EST), France (FRA), Hungary (HUN), Ireland (IRE), Italy (ITA), Lithuania (LTU), Luxembourg (LUX), Latvia (LVA), Netherlands (NED), Austria (OST), Poland (POL), Portugal (POR), Finland (SUO), Sweden (SVE), Slovenia (SVN), Slovakia (SVK), and the United Kingdom (UKI)), from 2005 to 2012, are used for the analysis. The FADN data set consists of annual accountancy data from a sample of commercial agricultural holdings in the EU. The data were collected by the Member States of the EU by following a harmonized bookkeeping principle (Commission 2016).

Within the countries of the EU, the Common Agricultural Policy (CAP) sets common farming regulations, e.g., with respect to environmental standards and subsidy payments (decoupled direct payments). Nevertheless, crop production systems differ due to farm structures, traditional differences, and especially due to agroclimatic conditions. To account for these differences, 
Table 1. Subsamples' Composition

\begin{tabular}{ll}
\hline Subsample & Countries \\
\hline North & SUO, SVE \\
East & EST, HUN, LTU, LVA, POL, SVN, SVK \\
South & ELL, ESP, ITA, POR \\
West & BEL, CZE, DAN, DEU, FRA, IRE, LUX, NED, OST, UKI \\
\hline
\end{tabular}

four subsamples (Table 1) were formed based on agroclimatic zones proposed by Bouma (2005). The subsamples North, East, South and West include the following different countries:

The farms in the samples produce a variety of outputs (i.e., crops, dairy, livestock) for which they rely on a variety of inputs. This study focuses on the characteristics of specialized crop-producing farms because these are most likely to engage in wheat production. Therefore, the farms selected from the sample include farms that generate at least 60 percent of their annual revenue by crop production in every year of observation. This results in an unbalanced panel based on a total of 73,719 observations after removing outliers from the sample. The farms remaining in the sample operated on an annual average area of 1,733,293 ha, which is approximately equal to 1.6 percent of European crop land (EUROSTAT 2016a). The average farm size in the sample is $186.5 \mathrm{ha}$, of which 70 ha on average were cultivated with wheat. The largest farms in the sample are in the Eastern region, where the average farm size is 230 ha.

The model estimation included specifying inputs and outputs based upon the production process of wheat farms. Two output variables are selected, namely total production of common wheat $\left(y_{1}^{t}\right)$ and total production of other field crops $\left(y_{2}^{t}\right)$, which account for all produced crops except wheat. Furthermore, five input variables were included, namely seed and plants $\left(x_{1}^{t}\right)$, fertilizers $\left(x_{2}^{t}\right)$, crop protection $\left(x_{3}^{t}\right)$, machinery $\left(x_{4}^{t}\right)$, labor $\left(x_{4}^{t}\right)$, and total crop area $\left(x_{5}^{t}\right)$. The variables measured in monetary terms $(€)$ refer to total production value $\left(y_{1}^{t}, y_{2}^{t}\right)$ and input expenditures $\left(x_{1}^{t}, x_{2}^{t}, x_{3}^{t}\right)$. All data measured in EUR were deflated using real agricultural price indices with the base year 2005 provided by the Eurostat database (EUROSTAT 2016b).

The analysis is conducted the entire sample as well as separately for the four subsamples (production regions North, East, South and West). The descriptive statistics for the entire sample are reported in Table 2.

From 2005 to 2012, the average total crops area per year in the sample remains almost constant in the range of 183-197 ha, and the average yearly wheat cultivation area ranges between 66 ha and 73 ha. Simultaneously, the total output of wheat varies between $571 € /$ ha and 1,256 $€$ /ha and indicates an upward trend over time. Expenditures for seeds and plants increased from $64 € /$ ha to $85 € /$ ha, while labor, on average, remained constant between $6,290 \mathrm{~h}$ and $6,991 \mathrm{~h}$. The included dummy variables to account for year $(Y)$, 
Table 2. Descriptive Statistics of the Sample Variables (Aggregated Sample)

\begin{tabular}{llrrrr}
\hline Variables (Obs: 75,784) & Unit & Mean & Min. & Max. & Std. Dev. \\
\hline $\begin{array}{l}\text { Outputs } \\
\begin{array}{l}\text { Common wheat total } \\
\text { production }\end{array}\end{array}$ & EUR & $64,584.7$ & 173.3 & $5,872,466$ & $143,783.1$ \\
$\begin{array}{l}\text { Other field crops total } \\
\text { production }\end{array}$ & EUR & $111,459.5$ & 146 & $9,589,848$ & $249,319.8$ \\
$\begin{array}{l}\text { Inputs } \\
\text { Total crops area }\end{array}$ & & & & & \\
$\begin{array}{l}\text { Seed and plants } \\
\text { Fertilizers }\end{array}$ & EUR & $13,175.2$ & 0 & $1,118,402$ & $32,801.5$ \\
$\begin{array}{l}\text { Crop protection } \\
\text { Machinery }\end{array}$ & EUR & $27,977.7$ & 0 & $2,004,995$ & $58,648.2$ \\
Labor & EUR & $19,953.1$ & 0 & $1,548,833$ & $44,025.3$ \\
\hline
\end{tabular}

Note: All monetary values are adjusted for inflation using the price indices for agricultural outputs and inputs with base year 2005 (EUROSTAT 2016b).

country $(C)$, and economic size $(E)$ are defined according to the FADN. It is assumed that $C$ picks up country differences in production systems, subsidy payments, and environmental conditions within a country. With respect to $E$, the FADN defines 14 different classes according to the standard output of farms (Commission 2016).

Different observations in the data set show 0 values for individual variables, which cannot be handled by the logarithmic functional specification. We follow the procedure outlines by Rasmussen (2010) and deleted those observations (a total of 2,287 observations were deleted). Only 3 percent of the sample was affected by this, and thus a significant bias is not expected with respect to the results.

In the empirical application of production or distance functions on agricultural holdings endogeneity is a general concern as discussed by, e.g., Kumbhakar (2001), Kumbhakar (2011), Brümmer, Glauben, and Thijssen (2002), Sauer and Latacz-Lohmann (2015), and Solís, Bravo-Ureta, and Quiroga (2009). Endogeneity problems occur in an IDF if outputs are not exogenously given. This problem occurs in agricultural crop production to a certain extent, because they are partly the result of exogenous climate factors and endogenous farming decisions. The endogeneity impact of outputs on the next season's inputs is less problematic in developed countries compared to developing countries where a bad harvest strongly influences the possibility to invest in next season's inputs. Farms in developed countries mostly follow a standard cultivation pattern that is far less influenced by the previous harvest outcome. Compared to multi-output production functions, DFs are 
superior in avoiding such endogeneity problems, although they fail avoiding them completely (Kumbhakar 2011). Because the inputs on the right-hand side of equation 4 appear as ratios, they are likely to suffer less from endogeneity (Brümmer, Glauben, and Thijssen 2002). Additionally, outputs are assumed to be exogenous to the farm's input choice to the extent that farms are cost minimizers, and panel data estimators control for farmers' input adjustment due to unobserved time-invariant conditions (Sauer and Wossink 2013).

\section{Empirical Results and Discussion}

This section presents the results for first-order elasticities, marginal shadow values, scale economies, technical efficiency, and technical change. Detailed estimates for the parameters of the IDF based on aggregated data for 23 European countries are presented in Table A1 (Appendix). In the estimation for the entire sample, we find more than 90 percent of the parameters to be statistically significant different from zero at least at the 5 percent level. Particularly, first-order coefficients and the dummy variables $Y, C$, and $E$ are mostly significant. A number of coefficients for the interaction variables (second order terms) are also significantly different from zero. This indicates non-linearities in the production structure and therefore supports the application of a flexible translog specification (Rahman 2009).

Applying the delta method, we derive the partial first-order elasticities of the translog function at the sample means for the entire EU region and the four subsamples as reported in Table 3. Furthermore, Table 3 reports the estimate of the MSV, SE, TE, and TC evaluated at the sample means.

The first-order derivatives or partial elasticities reflect input substitutability with respect to seeds $\left(\varepsilon_{x_{1}, x_{k}}\right)$ and marginal output contributions $\left(\varepsilon_{x_{1} y_{m}}\right)$. As the dependent variable in equation 7 is $-\ln x_{1}$, these estimates show negative signs for partial derivatives with respect to outputs and positive signs for partial derivatives with respect to inputs. The positive signs of all elasticities for the inputs imply their substitutability with total seed expenditures $\left(\partial \ln x_{1} / \partial \ln x_{k}<0\right)$. The negative signs of all elasticities for the outputs imply that a reduction in total seed expenditures $\left(x_{1}\right)$ is positively associated with a reduction in outputs $\left(\partial \ln x_{1} / \partial \ln y_{m}>0\right)$ (Rahman 2009). Thus, the estimations confirm the monotonicity conditions for the specified stochastic inputoriented distance frontier at the sample means (Rasmussen 2010). The (input) elasticities for outputs $\left(\varepsilon_{x_{1}, y_{m}}\right)$ represent the percentage in $x_{1}$ associated with a 1 percent change in $y_{m}$, holding all input ratios $\left(\ln \left(x_{k} / x_{1}\right)\right)$ constant. Because $x_{1}$ corresponds to the relative measure for the inputs, all other inputs need to change similar to $x_{1}$ in order to hold the input ratios constant. Thus, $\varepsilon_{X_{1} y_{m}}$ summarizes the (total) input expansion required for a 1 percent increase in $y_{m}$ and can be considered an input share of $y_{m}$ (relative to $x_{1}$ ) (Paul and Nehring 2005). For example, the elasticity of -0.24430 for 
Table 3. Elasticities MSV, SE, TE and TC (with delta method evaluated at the sample means)

\begin{tabular}{|c|c|c|c|c|c|c|}
\hline Region & & EU & North & East & South & West \\
\hline Obs. & & 73,719 & 1,626 & 29,527 & 8,670 & 33,896 \\
\hline \multicolumn{7}{|l|}{ Elasticities of outputs } \\
\hline$\varepsilon_{x_{1}, y_{1}}$ (wheat) & & -0.24430 & -0.21755 & -0.19222 & -0.21269 & -0.26205 \\
\hline$\varepsilon_{X_{1} y_{2}}$ (other crops) & & -0.30705 & -0.24065 & -0.26673 & -0.29854 & -0.29692 \\
\hline \multicolumn{7}{|l|}{ Elasticities of inputs } \\
\hline$\varepsilon_{x_{1}, x_{2}}$ (fertilizer) & & 0.07202 & 0.08624 & 0.07492 & 0.06833 & 0.07217 \\
\hline$\varepsilon_{x_{1}, x_{3}}$ (crop protection) & & 0.17717 & 0.12236 & 0.11490 & 0.12787 & 0.22985 \\
\hline$\varepsilon_{x_{1}, x_{4}}$ (machinery) & & 0.04143 & 0.03060 & 0.04458 & 0.02871 & 0.03592 \\
\hline$\varepsilon_{x_{1}, x_{5}}$ (labor) & & 0.26246 & 0.21145 & 0.26812 & 0.31773 & 0.25176 \\
\hline$\varepsilon_{X_{1}, x_{6}}$ (total crop area) & & 0.30212 & 0.42679 & 0.37014 & 0.29511 & 0.26125 \\
\hline MSV (yield increasing wheat seeds in €) & $\begin{array}{l}\text { Farm total } \\
\text { Per ha }\end{array}$ & $\begin{array}{r}1,303.46 \\
18.87\end{array}$ & $\begin{array}{r}838.90 \\
17.97\end{array}$ & $\begin{array}{r}916.58 \\
12.79\end{array}$ & $\begin{array}{r}635.95 \\
31.85\end{array}$ & $\begin{array}{r}1500.70 \\
15.60\end{array}$ \\
\hline $\operatorname{SE}\left(\varepsilon_{\boldsymbol{x}_{1}, \boldsymbol{y}}\right)$ & & 0.52030 & 0.45819 & 0.45895 & 0.51123 & 0.55897 \\
\hline TE (within the subsample) & & 0.91203 & 0.90680 & 0.91561 & 0.88820 & 0.98908 \\
\hline TC & & $-0.291 \%$ & $-0.09 \%$ & $0.23 \%$ & $-0.25 \%$ & $-0.192 \%$ \\
\hline
\end{tabular}

Note: Marginal shadow value (MSV), scale economies (SE), technical efficiency (TE), technical change (TC). 
wheat output $\left(\varepsilon_{x_{1}, y_{1}}\right)$ implies that a 1 percent increase in wheat production is associated with a 0.24430 percent increase in (all) inputs, measured at the sample mean and holding all input ratios constant.

In a manner similar to $\varepsilon_{x_{1}, y_{m}}$, the elasticities for the inputs $\left(\varepsilon_{x_{1}, x_{k}}\right)$ represent the percentage change of $x_{1}$ associated with a 1 percent change in $x_{k}$. However, in an IDF (equation 7) $x_{k}$ is measured relative to $x_{1}$. For example, the elasticity value of 0.30212 for the input land $\left(\varepsilon_{x_{1}, x_{6}}\right)$ implies that a 1 percent decrease in the ratio of land $\left(x_{6}\right)$ to seeds $\left(x_{1}\right)$, due to a change in $x_{6}$, could be substituted by 0.30212 percent increase in all inputs. Again, this change, which would keep production constant, is measured at the sample means.

For every subsample, $\varepsilon_{x_{1} y_{2}}$ is found to exceed $\varepsilon_{X_{1} y_{1}}$, which confirms that the production of $y_{2}$ (crops other than wheat) requires a higher input share for farms at the sample means. The estimates for the partial elasticities of inputs $\left(\varepsilon_{x_{1} \cdot x_{k}}\right)$ represent their proportional marginal productivity. The variables land $\left(\varepsilon_{x_{1} . x_{5}}\right)$ and labor $\left(\varepsilon_{x_{1}, x_{6}}\right)$ show the largest magnitudes, and this suggests that these are the inputs with the highest contribution to outputs within the estimated models.

\section{Technical Efficiency and Technical Change}

The results indicated that technical efficiency (TE) remains fairly constant over time and varies between 0.896 and 0.925 at the aggregated EU level. The estimates exceed that in a previous study of the TE of European crop farmers by Rasmussen (2010), where a value of 0.82 was determined based on data from 1985 to 2006. However, Paul and Nehring (2005) determined a higher TE of crop farms in the U.S. corn belt of 0.94 from 1996 to 2000. It is important to note that TE is only measured within each subsample and only comparable to a limited extent between different subsamples.

The rate of technical change (TC) can be calculated using the derivative of the DF (in logs) with respect to $t\left(\varepsilon_{D_{i}, t}=\partial \ln D_{i} / \partial t\right)$ (Kumbhakar, Asche, and Tveteras 2013). We determine an average annual TC of -0.291 percent, thereby implying a negative technical change over time, albeit at a relatively low rate. In contrast, Sauer and Latacz-Lohmann (2015) analyzed German dairy farms from 19962010 and found a positive average annual technical change of 1.5 percent.

\section{Scale Economies}

The negative sum of elasticities of outputs $\left(\varepsilon_{x_{1} y_{m}}\right)$ represents scale economies (SE) at the sample means. Thus, it reflects the extent to which overall input use must increase to support a 1 percent increase in all outputs (Paul and Nehring 2005). Values below 1 imply that the production possibility frontier expands more than proportionally with an increase in resources, which indicates increasing returns to scale. Accordingly, an SE value of 0.5203 (Table 3) indicates that a 0.5203 percent increase in all inputs is required to sustain a 1 percent increase in outputs. Thus, on average, European crop 


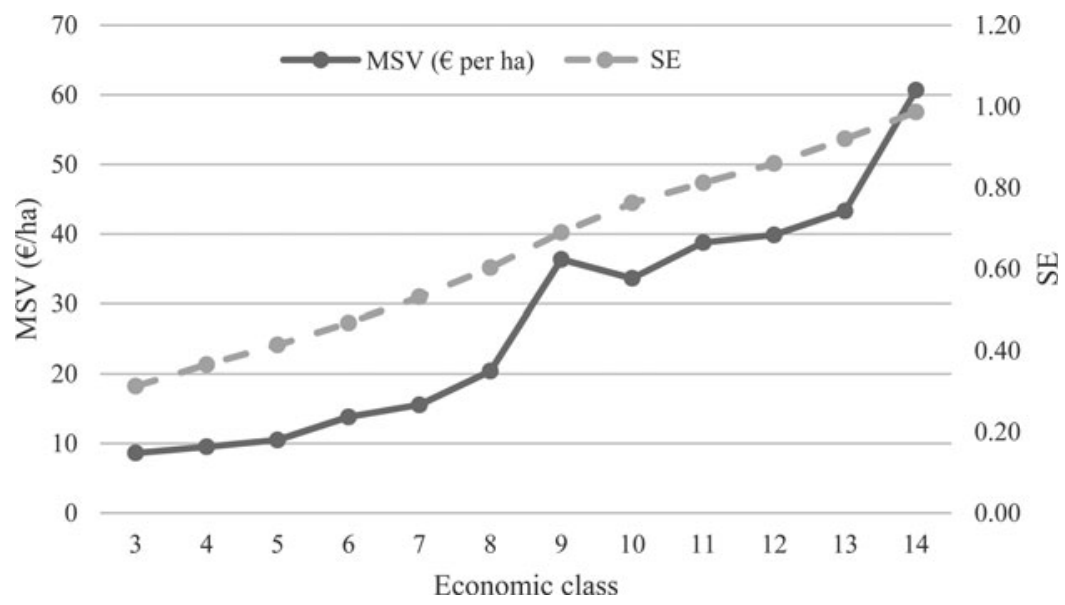

Figure 1. Average MSV and SE relative to Economic Class.

farmers are likely to benefit from economies of scale. Figure 1 shows increasing SE with increasing economic size, which indicates that farms in higher economic classes are closer to the optimal farm size. We derive low SE values at the sample mean similar to previous European farms studies including Paul and Nehring (2005) (SE value of 0.654) and Fleming and Lien (2009) (SE value of 0.700 ).

The analysis provides detailed insight into the European crop production system. However, due to data aggregation and availability, it is not possible to check specifically for farm individual aspects, such as soil quality or farmers' characteristics. For example, Sauer and Latacz-Lohmann (2015) show in their DF model that the farmers' age and education level affect efficiency and investment in innovations.

\section{Marginal Shadow Value}

We estimate an average MSV for yield-increasing seed material of $18.87 € /$ ha for the average European crop farm. Depending on the region, this value varies between $15.60 € /$ ha and $31.85 € /$ ha (Table 3). The reason for these differences is not easy to identify but can rather be considered a result of complex differences in regional crop production systems and technologies influenced by factors such as climate conditions, farm structure, and land and labor availability. Further, because the MSV measures a percentage increase of absolute terms, one can expect a region with generally lower revenue/ha - e.g., the North and East regions - to show a lower MSV/ha. Within the total sample, we identify increasing average MSVs with an increase in economic class (Figure 1). Consequently, farmers in a higher economic class could pay a higher price for yield-increasing seeds. 
Incremental revenue from a 1 percent yield increase in wheat are, on average, $92.9 € /$ ha for EU crop farms. The MSV for the input seed is 20.3 percent of this value. The result is consistent with production theory because the incremental use of different substitutable inputs could lead to a yield increase. Elasticities indicate the marginal output effect for individual inputs. Thus, the MSV for one specific input must always be smaller than the incremental revenue due to substitutability.

\section{Robustness}

Various specifications of the model were compared based on likelihood ratio tests, for which the results are presented in Table A2 (Appendix). We tested for systematic differences between the model with different subgroups (specialized crop farms and general farms), with and without dummy variables (year, country, and economics size), and with and without a time variable to include technical change. The test results support the sampling decision at statistically significant levels. Further, we find the chosen translog functional form superior to a Cobb-Douglas functional form. The hypothesis of no inefficiencies in the model was rejected at least at a 10 percent level for all four subgroups.

\section{Conclusions}

In the preceding analysis, we estimated translog IDFs for a comprehensive unbalanced panel of European farms (FADN data) for the period from 2005 to 2012. We evaluate a range of measures capturing the output-input relationships for European crop farms. Additionally, we exploited the duality between the IDF and the cost function to determine MSV of marginal yieldincreasing breeding innovations in wheat for four European crop production regions. On average, we derived MSV of $18.87 € /$ ha for European crop farms. However, farm individual MSVs will differ from that value due to general differences in regions, economic classes and SE.

Our findings give valuable information to farmers, seed producers, and other political stakeholders. The derived MSVs indicate the marginal economic value of breeding innovations. Those breeding innovation's benefits are usually shared between the seed developer, the farmer, and to a lower extent the consumer, but the percentage distribution of the shares can be very different based on the region and trait (Qaim 2009). In our model, the MSVs for seeds indicate the economic value of crop improvements to farms. However, through seed prices or breeding premiums, innovation's benefits are shared between the seed developer and the farmer. Furthermore, yield increases provide social benefits in terms of food security and offer potential benefits for environmental conservation and resource savings. MSVs give theoretical values for breeding innovations; however, the actual values are also determined by practical circumstances, such as laws and agreements. The 
International Union for the Protection of New Varieties of Plants (UPOV) aims to protect breeding innovations for the benefit of society through the application of an effective regulatory system. Not all countries in our sample signed the latest UPOV act. ${ }^{1}$ In a weak regulatory system, MSV and long-term benefits of breeding innovations might be lost.

Generally, the results of the present study are independent from any breeding techniques such as conventional, hybrid, and GM. The suggested MSV approach can also be applied to economically evaluate marginal improvements in other production factors.

\section{References}

Arandia, A. and A. Aldanondo-Ochoa. 2011. "Pollution Shadow Prices in Conventional and Organic Farming: An Application in A Mediterranean Context." Spanish Journal of Agricultural Research 9(2): 363-376.

Battese, G.E. and T.J. Coelli. 1992. "Frontier Production Functions, Technical Efficiency and Panel Data: With Application to Paddy Farmers in India." In International Applications of Productivity and Efficiency Analysis 3(1), 153-169. https://doi.org/10.1007/ BF00158774

Bouma, E. 2005. "Development of Comparable Agro-Climatic Zones for the International Exchange of Data on the Efficacy and Crop Safety of Plant Protection products1." EPPO Bulletin 35(2): 233-238.

Brookes, G. and P. Barfoot. 2014. GM Crops: Global Socio-economic and Environmental Impacts 1996-2012. Dorchester, UK: PG Economics Ltd.

Brümmer, B., T. Glauben, and G. Thijssen. 2002. "Decomposition of Productivity Growth Using Distance Functions: The Case of Dairy Farms in Three European Countries." American Journal of Agricultural Economics 84(3): 628-644.

Coelli, T. and E. Fleming. 2004. "Diversification Economies and Specialisation Efficiencies in A Mixed Food and Coffee Smallholder Farming System in Papua New Guinea." Agricultural Economics 31(2-3): 229-239.

Coelli, T. and S. Perelman. 1996. Efficiency measurement, multiple-output technologie and distance functions: With application to European Railways. Centre de Recherche en Economie, Publique (CREPP).

— 1999. "A Comparison of Parametric and Non-parametric Distance Functions: With Application to European Railways." European Journal of Operational Research 117(2): 326-339.

Commission, E. 2016. Farm Accountancy Data Network (FADN). Brussels: European Commission. Available at http://ec.europa.eu/agriculture/fadn/index_en.htm (accessed June 2016).

EUROSTAT. 2016a. Land Cover 2012 LUCAS2012. Luxembourg: EUROSTAT. Available at http://ec.europa.eu/eurostat/statistics-explained/index.php/File:Land_cover,_2012_ LUCAS2012.png (accessed June 2016).

- 2016b. Price Indices of Agricultural Products, Output $(2005=100)$-Annual Data. Luxembourg: EUROSTAT. Available at http://ec.europa.eu/eurostat/data/database (accessed June 2016).

1 Luxembourg and Greece have not signed any form of UPOV, Belgium is still under the 1972 act, and Portugal is under the 1978 act. 
FAOSTAT. 2016. Food and Agriculture Organization of the United Nations, Statistics Division. Rome: FAOSTAT. Available at http://faostat3.fao.org/download (accessed June 2016).

Färe, R., S. Grosskopf, and W.L. Weber. 2006. "Shadow Prices and Pollution Costs in US Agriculture." Ecological Economics 56(1): 89-103.

Färe, R. and D. Primont. 1995. Multi-output Production and Duality: Theory and Applications. Boston, MA.: Kluwer Academic Publishers.

_. 2006. "Directional Duality Theory Directional Duality Theory." Economic Theory 29(1): 239-247.

Fleming, E. and G. Lien. 2009. "Synergies, Scope Economies and Scale Diseconomies on Farms in Norway." Acta Agriculturae Scandinavia Section C 6(1): 21-30.

Hailu, A. and T.S. Veeman. 2001. "Non-parametric Productivity Analysis with Undesirable Outputs: An Application to the Canadian Pulp and Paper Industry." American Journal of Agricultural Economics 83(3): 605-616.

Key, N. and S. Sneeringer. 2014. "Potential Effects of Climate Change on the Productivity of US Dairies." American Journal of Agricultural Economics 96(4): 1136-1156.

Kodde, D.A. and F.C. Palm. 1986. "Wald Criteria for Jointly Testing Equality and Inequality Restrictions." Econometrica: Journal of the Econometric Society 54(5): 1243-1248.

Kumbhakar, S.C. 2001. "Estimation of Profit Functions When Profit is not Maximum." American Journal of Agricultural Economics 83(1): 1-19.

2011. Estimation of Multiple Output Production Functions. Tech. rep., Department of Economics. Available at https://www.researchgate.net/profile/Subal_Kumbhakar/ publication/267861010_Estimation_of_Multiple_Output_Production_Functions/links/ 550ac3080cf265693cedbac9/Estimation-of-Multiple-Output-Production-Functions.pdf (Accessed February 12, 2018).

Kumbhakar, S.C., F. Asche, and R. Tveteras. 2013. "Estimation and Decomposition of Inefficiency When Producers Maximize Return to the Outlay: An Application to Norwegian Fishing Trawlers." Journal of Productivity Analysis 40(3): 307-321.

Kumbhakar, S.C., H. Wang, and A.P. Horncastle. 2015. A Practitioner's Guide to Stochastic Frontier Analysis Using Stata. Cambridge University Press.

Longin, C.F.H., M. Gowda, J. Mühleisen, E. Ebmeyer, E. Kazman, R. Schachschneider, J. Schacht, M. Kirchhoff, Y. Zhao, and J.C. Reif. 2013. "Hybrid Wheat: Quantitative Genetic Parameters and Consequences for the Design of Breeding Programs." Theoretical and Applied Genetics 126(11): 2791-2801.

Newman, C. and A. Matthews. 2006. "The Productivity Performance of Irish Dairy Farms 1984-2000: A Multiple Output Distance Function Approach." Journal of Productivity Analysis 26(2): 191-205.

Njuki, E. and B.E. Bravo-Ureta. 2015. "The Economic Costs of Environmental Regulation in US Dairy Farming: A Directional Distance Function Approach." American Journal of Agricultural Economics 97(4): 1087-1106.

Paul, C.J.M. and R. Nehring. 2005. "Product Diversification, Production Systems, and Economic Performance in US Agricultural Production." Journal of Econometrics 126(2): $525-548$.

Qaim, M. 2009. "The Economics of Genetically Modified Crops." Annual Review of Resource Economics 1(1): 665-694.

Rahman, S. 2009. "Whether Crop Diversification is A Desired Strategy for Agricultural Growth in Bangladesh?" Food Policy 34(4): 340-349.

Rasmussen, S. 2010. "Scale Efficiency in Danish Agriculture: An Input Distance-Function Approach." European Review of Agricultural Economics 37(3): 335-367.

Reinhard, S., C.K. Lovell, and G. Thijssen. 1999. "Econometric Estimation of Technical and Environmental Efficiency: An Application to Dutch Dairy Farms." American Journal of Agricultural Economics 81(1): 44-60.

Saalbach, I., I. Mora-Ramírez, N. Weichert, F. Andersch, G. Guild, H. Wieser, P. Koehler, J. Stangoulis, J. Kumlehn, and W. Weschke. 2014. "Increased Grain Yield and 
Micronutrient Concentration in Transgenic Winter Wheat by Ectopic Expression of a Barley Sucrose Transporter." Journal of Cereal Science 60(1): 75-81.

Sauer, J., K. Frohberg, and H. Hockmann. 2006. "Stochastic Efficiency Measurement: The Curse of Theoretical Consistency." Journal of Applied Economics 9(1): 139-165.

Sauer, J. and U. Latacz-Lohmann. 2015. "Investment, Technical Change and Efficiency: Empirical Evidence from German Dairy Production." European Review of Agricultural Economics 42(1): 151-175.

Sauer, J. and A. Wossink. 2013. "Marketed Outputs and Non-marketed Ecosystem Services: The Evaluation of Marginal Costs." European Review of Agricultural Economics 40(4): 573-603.

Shephard, R.W. 1970. Theory of Cost and Production Functions Princeton University Press. New Jersey: Princeton.

Shiferaw, B., M. Smale, H.-J. Braun, E. Duveiller, M. Reynolds, and G. Muricho. 2013. "Crops That Feed the World 10. Past Successes and Future Challenges to the Role Played by Wheat in Global Food Security." Food Security 5(3): 291-317.

Solís, D., B.E. Bravo-Ureta, and R.E. Quiroga. 2009. “Technical Efficiency among Peasant Farmers Participating in Natural Resource Management Programmes in Central America." Journal of Agricultural Economics 60(1): 202-219.

Tsionas, E.G., S.C. Kumbhakar, and E. Malikov. 2015. "Estimation of Input Distance Functions: A System Approach." American Journal of Agricultural Economics 97(5). https://doi.org/ 10.1093/ajae/aav012.

Zhou, P., X. Zhou, and L. Fan. 2014. “On Estimating Shadow Prices of Undesirable Outputs with Efficiency Models: A Literature Review." Applied Energy 130: 799-806.

Zilberman, D., G. Graff, G. Hochman, and S. Kaplan. 2015. "The Political Economy of Biotechnology." German Journal of Agricultural Economics 64(4): 212-223. 


\section{Appendix}

Tables A1 and A2.

Table A1. Estimation Results: Multi-output Multi-input Stochastic IDF for All European Countries

\begin{tabular}{|c|c|c|c|c|}
\hline Total crops area & Parameters & Coeff. & Std. Err. & $\mathbf{P}>|\mathbf{z}|$ \\
\hline \multicolumn{5}{|l|}{ Frontier } \\
\hline $\ln ($ wheat $)$ & $\beta_{1}$ & 0.1854413 & & 0.000 \\
\hline $\ln$ (other crops) & $\beta_{2}$ & 0.0542069 & & 0.000 \\
\hline $\ln ($ wheat $) \times \ln ($ wheat $)$ & $\beta_{11}$ & -0.1211454 & & 0.000 \\
\hline $\ln ($ wheat $) \times \ln ($ other crops $)$ & $\beta_{12}$ & 0.057113 & & 0.000 \\
\hline $\ln ($ other crops $) \times \ln ($ other crops $)$ & $\beta_{22}$ & -0.115165 & & 0.000 \\
\hline $\ln ($ wheat $) \times \ln ($ fertilizer $)$ & $\delta_{12}$ & 0.0212942 & & 0.000 \\
\hline $\ln ($ wheat $) \times \ln ($ crop protection $)$ & $\delta_{13}$ & -0.0126239 & & 0.000 \\
\hline $\ln ($ wheat $) \times \ln ($ machinery $)$ & $\delta_{14}$ & 0.0077065 & & 0.000 \\
\hline $\ln ($ wheat $) \times \ln ($ labor $)$ & $\delta_{15}$ & -0.0524704 & & 0.000 \\
\hline $\ln ($ wheat $) \times \ln ($ land $)$ & $\delta_{16}$ & 0.0599189 & & 0.000 \\
\hline $\ln ($ other crops $) \times \ln ($ fertilizer $)$ & $\delta_{22}$ & 0.0025249 & & 0.285 \\
\hline $\ln ($ other crops $) \times \ln ($ crop protection $)$ & $\delta_{23}$ & 0.0184444 & & 0.000 \\
\hline $\ln ($ other crops $) \times \ln ($ machinery $)$ & $\delta_{24}$ & 0.0108085 & & 0.000 \\
\hline $\ln ($ other crops $) \times \ln ($ labor $)$ & $\delta_{25}$ & 0.0125612 & & 0.000 \\
\hline $\ln ($ other crops $) \times \ln ($ land $)$ & $\delta_{26}$ & -0.0615178 & & 0.000 \\
\hline $\ln ($ fertilizer $)$ & $\alpha_{2}$ & -0.1002692 & & 0.000 \\
\hline $\ln ($ crop protection) & $\alpha_{3}$ & 0.1807334 & & 0.000 \\
\hline
\end{tabular}


Table A1. Continued

\begin{tabular}{|c|c|c|c|c|}
\hline Total crops area & Parameters & Coeff. & Std. Err. & $\mathbf{P}>|\mathbf{z}|$ \\
\hline $\ln ($ machinery) & $\alpha_{4}$ & -0.1360751 & & 0.000 \\
\hline $\ln ($ labor) & $\alpha_{5}$ & 0.3568976 & & 0.000 \\
\hline $\ln ($ land) & $\alpha_{6}$ & 0.2852327 & & 0.000 \\
\hline $\ln ($ fertilizer $) \times \ln ($ fertilizer $)$ & $\alpha_{22}$ & 0.044459 & & 0.000 \\
\hline $\ln ($ fertilizer $) \times \ln$ (crop protection) & $\alpha_{23}$ & -0.0326878 & & 0.000 \\
\hline $\ln ($ fertilizer $) \times \ln ($ machinery $)$ & $\alpha_{24}$ & -0.0103323 & & 0.000 \\
\hline $\ln ($ fertilizer $) \times \ln ($ labor $)$ & $\alpha_{25}$ & 0.0056864 & & 0.028 \\
\hline $\ln ($ fertilizer $) \times \ln ($ land $)$ & $\alpha_{26}$ & 0.0114391 & & 0.001 \\
\hline $\ln ($ crop protection $) \times \ln ($ crop protection $)$ & $\alpha_{33}$ & 0.0814748 & & 0.000 \\
\hline $\ln ($ crop protection $) \times \ln ($ machinery $)$ & $\alpha_{34}$ & -0.007717 & & 0.000 \\
\hline $\ln ($ crop protection $) \times \ln ($ labor $)$ & $\alpha_{35}$ & -0.0050478 & & 0.019 \\
\hline $\ln ($ crop protection $) \times \ln ($ land $)$ & $\alpha_{36}$ & -0.0137855 & & 0.000 \\
\hline $\ln ($ machinery $) \times \ln ($ machinery $)$ & $\alpha_{55}$ & 0.0160653 & & 0.000 \\
\hline $\ln ($ machinery $) \times \ln ($ labor $)$ & $\alpha_{56}$ & 0.0098117 & & 0.000 \\
\hline $\ln ($ machinery $) \times \ln ($ land $)$ & $\alpha_{57}$ & 0.006551 & & 0.000 \\
\hline $\ln$ (labor) $\times \ln$ (labor) & $\alpha_{66}$ & 0.0176325 & & 0.000 \\
\hline $\ln ($ labor $) \times \ln ($ land $)$ & $\alpha_{67}$ & 0.0161114 & & 0.000 \\
\hline $\ln ($ land $) \times \ln ($ land $)$ & $\alpha_{77}$ & -0.0263266 & & 0.000 \\
\hline$t$ & $\omega_{0}$ & -0.7897497 & & 0.000 \\
\hline$t^{2}$ & $\omega_{00}$ & 0.107003 & & 0.001 \\
\hline $\ln (\text { wheat })_{-} t$ & $\zeta_{1 \mathrm{t}}$ & 0.0060681 & & 0.000 \\
\hline $\ln ($ other crops)_t & $\zeta_{1 \mathrm{t}}$ & -0.0075074 & & 0.000 \\
\hline $\ln ($ fertilizer)_t & $\eta_{2 t}$ & 0.0059123 & & 0.000 \\
\hline
\end{tabular}




\begin{tabular}{|c|c|c|c|}
\hline $\ln ($ crop protection)_t & $\eta_{3 t}$ & -0.0018287 & 0.004 \\
\hline $\ln ($ machinery)_t & $\eta_{4 \mathrm{t}}$ & 0.0006367 & 0.078 \\
\hline $\ln$ (labor)_t & $\eta_{5 t}$ & -0.000369 & 0.515 \\
\hline $\ln (\text { land })_{-} t$ & $\eta_{6 t}$ & -0.000712 & 0.417 \\
\hline year_dummy2005 & & -2.150663 & 0.000 \\
\hline year_dummy2006 & & -1.540443 & 0.000 \\
\hline year_dummy2007 & & -1.081107 & 0.000 \\
\hline year_dummy2008 & & -0.6909532 & 0.000 \\
\hline year_dummy2009 & & -0.2313109 & 0.000 \\
\hline year_dummy2010 & & 0 (omitted) & \\
\hline year_dummy2011 & & 0 (omitted) & \\
\hline year_dummy2012 & & 0 (omitted) & \\
\hline country_dummyBEL & & 0.1588165 & 0.000 \\
\hline country_dummyCZE & & -0.313934 & 0.000 \\
\hline country_dummyDAN & & 0.2093997 & 0.000 \\
\hline country_dummyDEU & & 0.0316546 & 0.000 \\
\hline country_dummyELL & & -0.0281328 & 0.009 \\
\hline country_dummyESP & & -0.0404519 & 0.000 \\
\hline country_dummyEST & & -0.4865652 & 0.000 \\
\hline country_dummyFRA & & 0.0165101 & 0.000 \\
\hline country_dummyHUN & & -0.260656 & 0.000 \\
\hline country_dummyIRE & & -0.056374 & 0.002 \\
\hline country_dummyITA & & 0.1217846 & 0.000 \\
\hline country_dummyLTU & & -0.3860692 & 0.000 \\
\hline
\end{tabular}


Table A1. Continued

\begin{tabular}{|c|c|c|c|c|}
\hline Total crops area & Parameters & Coeff. & Std. Err. & $\mathbf{P}>|\mathbf{z}|$ \\
\hline country_dummyLUX & & -0.1585622 & & 0.000 \\
\hline country_dummyLVA & & -0.4901362 & & 0.000 \\
\hline country_dummyNED & & 0.1818278 & & 0.000 \\
\hline country_dummyOST & & 0.0427528 & & 0.000 \\
\hline country_dummyPOL & & -0.2660551 & & 0.000 \\
\hline country_dummyPOR & & -0.3094652 & & 0.000 \\
\hline country_dummySUO & & -0.1657136 & & 0.455 \\
\hline country_dummySVE & & -0.1657136 & & 0.000 \\
\hline country_dummySVK & & -0.4963437 & & 0.000 \\
\hline country_dummySVN & & -0.0714956 & & 0.000 \\
\hline country_dummyUKI & & 0 (omitted) & & \\
\hline EcoSize_dummy1 & & 1.477931 & & 0.000 \\
\hline EcoSize_dummy2 & & 1.289724 & & 0.000 \\
\hline EcoSize_dummy3 & & 1.122759 & & 0.000 \\
\hline EcoSize_dummy4 & & 0.9272114 & & 0.000 \\
\hline EcoSize_dummy5 & & 0.7325038 & & 0.000 \\
\hline EcoSize_dummy6 & & 0.5290397 & & 0.000 \\
\hline EcoSize_dummy7 & & 0.3269214 & & 0.000 \\
\hline EcoSize_dummy8 & & 0.1816877 & & 0.000 \\
\hline EcoSize_dummy9 & & 0.0856994 & & 0.000 \\
\hline EcoSize_dummy10 & & 0.0525546 & & 0.004 \\
\hline EcoSize_dummy11 & & -0.0175358 & & 0.310 \\
\hline EcoSize_dummy12 & & 0 (omitted) & & \\
\hline
\end{tabular}


Constant

Usigmas

$t$

Constant

vsigmas

Constant

Log likelihood: 5510.9927

Number of observation: 73719

Wald chi ${ }^{2}$ (82): 2412373.29

Prob $>$ chi $^{2}: 0.0000$

Note: The dummy variables year_dummyXXXX, country_dummyXXX and EcoSize_dummyXX control for different years, countries and economic sizes in the sample, respectively. The economic size classes are defined according to the FADN. The coefficient cannot be interpreted directly. Using the delta method relevant coefficients are presented in Table 3. 
Table A2. Log Likelihood Test Ratios

\begin{tabular}{|c|c|c|c|c|c|}
\hline \multirow[t]{2}{*}{ Test } & \multirow[t]{2}{*}{ Hypothesis } & \multicolumn{4}{|l|}{ Region } \\
\hline & & North & East & South & West \\
\hline Subsamples & $\begin{array}{l}\mathrm{H}_{0}: \text { Specialized and non- } \\
\text { specialized farms share the } \\
\text { same technology } \mathrm{H}_{\mathrm{A}} \text { : } \\
\text { Specialized and non- } \\
\text { specialized farms have } \\
\text { different technology }\end{array}$ & $\begin{array}{l}\text { Test-statistic: } \\
479.74 \\
\text { Critical value: } \\
\chi_{62 .}^{2} 0.01=90.80 \\
\text { Rejected at } \\
\quad 0.01 \% \\
\quad \text { significance }\end{array}$ & $\begin{array}{l}\text { Test-statistic: } \\
1373.00 \\
\text { Critical value: } \\
\chi_{70.0 .01}^{2}=100.43 \\
\text { Rejected at } 0.01 \% \\
\quad \text { significance }\end{array}$ & $\begin{array}{l}\text { Test-statistic: } \\
363.28 \\
\text { Critical value: } \\
\chi_{67 .}^{2} 0.01=96.82 \\
\text { Rejected at } \\
\quad 0.01 \% \\
\quad \text { significance }\end{array}$ & $\begin{array}{l}\text { Test-statistic: } \\
11221.92 \\
\text { Critical value: } \\
\chi_{68.0 .01}^{2}=131.14 \\
\text { Rejected at } 0.01 \% \\
\quad \text { significance }\end{array}$ \\
\hline $\begin{array}{l}\text { Dummy variables } \\
\text { (country) }\end{array}$ & $\begin{array}{l}\mathrm{H}_{0} \text { : Including country } \\
\text { dummy variables does not } \\
\text { improve the model fitness } \\
\mathrm{H}_{\mathrm{A}} \text { : Including country } \\
\text { dummy variables does } \\
\text { improve the model fitness }\end{array}$ & $\begin{array}{l}\text { Test-statistic: } \\
130.88- \\
\text { Critical value: } \\
\chi_{1 .}^{2} 0.01=6.63 \\
\text { Rejected at } \\
\quad 0.01 \% \\
\quad \text { significance }\end{array}$ & $\begin{array}{l}\text { Test-statistic: } \\
2026.82 \\
\text { Critical value: } \\
\chi_{6.0 .01}^{2}=16.81 \\
\text { Rejected at } 0.01 \% \\
\quad \text { significance }\end{array}$ & $\begin{array}{l}\text { Test-statistic: } \\
484.19 \\
\text { Critical value: } \\
\chi_{3 .}^{2} 0.01=11.34 \\
\text { Rejected at } \\
\quad 0.01 \% \\
\quad \text { significance }\end{array}$ & $\begin{array}{l}\text { Test-statistic: } \\
1750.08 \\
\text { Critical value: } \\
\chi_{9.0 .01}^{2}=21.67 \\
\text { Rejected at } 0.01 \% \\
\quad \text { significance }\end{array}$ \\
\hline $\begin{array}{l}\text { Dummy variables } \\
\text { (economic size) }\end{array}$ & $\begin{array}{l}\mathrm{H}_{0} \text { : Including economic size } \\
\text { dummy variables does not } \\
\text { improve the model fitness } \\
\mathrm{H}_{\mathrm{A}} \text { : Including economic size } \\
\text { dummy variables does } \\
\text { improve the model fitness }\end{array}$ & $\begin{array}{l}\text { Test-statistic: } \\
336.64 \\
\text { Critical value: } \\
\chi_{08 .}^{2} 0.01=20.09 \\
\text { Rejected at } \\
\quad 0.01 \% \\
\quad \text { significance }\end{array}$ & $\begin{array}{l}\text { Test-statistic: } \\
10279.32 \\
\text { Critical value: } \\
\chi_{11.0 .01}^{2}=24.72 \\
\text { Rejected at } 0.01 \% \\
\quad \text { significance }\end{array}$ & $\begin{array}{l}\text { Test-statistic: } \\
1482.25 \\
\text { Critical value: } \\
\chi_{11.0 .01}^{2}=24.72 \\
\text { Rejected at } \\
\quad 0.01 \% \\
\quad \text { significance }\end{array}$ & $\begin{array}{l}\text { Test-statistic: } \\
5694.92 \\
\text { Critical value: } \\
\chi_{10.0 .01}^{2}=23.21 \\
\text { Rejected at } 0.01 \% \\
\quad \text { significance }\end{array}$ \\
\hline $\begin{array}{l}\text { Dummy variables } \\
\text { (year) }\end{array}$ & $\begin{array}{l}\mathrm{H}_{0} \text { : Including year dummy } \\
\text { variables does not improve } \\
\text { the model fitness } \mathrm{H}_{\mathrm{A}} \text { : } \\
\text { Including year dummy } \\
\text { variables does improve the } \\
\text { model fitness }\end{array}$ & $\begin{array}{l}\text { Test-statistic: } \\
120.43 \\
\text { Critical value: } \\
\chi_{5.0 .01}^{2}=15.09 \\
\text { Rejected at } \\
\quad 0.01 \% \\
\quad \text { significance }\end{array}$ & $\begin{array}{l}\text { Test-statistic: } \\
1919.40 \\
\text { Critical value: } \\
\chi_{5.0 .01}^{2}=15.09 \\
\text { Rejected at } 0.01 \% \\
\quad \text { significance }\end{array}$ & $\begin{array}{l}\text { Test-statistic: } \\
360.92 \\
\text { Critical value: } \\
\chi_{5 .}^{2} 0.01=15.09 \\
\text { Rejected at } \\
\quad 0.01 \% \\
\quad \text { significance }\end{array}$ & $\begin{array}{l}\text { Test-statistic: } \\
1277.45 \\
\text { Critical value: } \\
\chi_{38.0 .01}^{2}=15.09 \\
\text { Rejected at } 0.01 \% \\
\quad \text { significance }\end{array}$ \\
\hline
\end{tabular}


Time variable

Cobb-Douglas

functional type

Inefficiency (critical $\chi^{2}$ values according to Kodde and Palm (1986))
$\mathrm{H}_{0}$ : Including a time variable does not improve the model fitness $\mathrm{H}_{\mathrm{A}}$ : Including a time variable does improve the model fitness

$\mathrm{H}_{0}$ : Cobb-Douglas functional type $\mathrm{H}_{\mathrm{A}}$ : Translog DF

$\mathrm{H}_{0}$ : No technical inefficiency present $\mathrm{H}_{\mathrm{A}}$ : Technical inefficiency present
Test-statistic:

43.51

Critical value:

$\chi_{8.0 .01}^{2}=20.09$

Rejected at

$0.01 \%$

significance

Test-statistic:

188.34

Critical value:

$\chi_{28.0 .01}^{2}=48.28$

Rejected at

$0.01 \%$

significance

Test-statistic:

2.47

Critical value:

Mixed

$\chi_{1.0 .01}^{2}=5.412$

Rejected at $0.1 \%$

significance
Test-statistic:

272.39

Critical value:

$\chi_{7.0 .01}^{2}=18.48$

Rejected at $0.01 \%$

significance

Test-statistic:

4028.13 Critical

value:

$\chi_{28.0 .01}^{2}=48.28$

Rejected at $0.01 \%$

significance

Test-statistic:

14.2521 .90

Critical value:

Mixed

$\chi_{1.0 .01}^{2}=5.412$

Rejected at $0.01 \%$ significance
Test-statistic:

93.10

Critical value:

$\chi_{7.0 .01}^{2}=18.48$

Rejected at

$0.01 \%$

significance

Test-statistic:

1487.04

Critical value:

$\chi_{\text {28. } 0.01}^{2}=48.28$

Rejected at

$0.01 \%$

significance

Test-statistic:

8.03

Critical value:

Mixed

$\chi_{1.0 .01}^{2}=5.412$

Rejected at

$0.01 \%$

significance
Test-statistic:

202.30

Critical value:

$\chi_{7.0 .01}^{2}=18.48$

Rejected at $0.01 \%$

significance

Test-statistic:

2021.14

Critical value:

$\chi_{28,0.01}^{2}=48.28$

Rejected at $0.01 \%$ significance

Test-statistic:

9818.42

Critical value:

Mixed

$\chi_{1.0 .01}^{2}=5.412$

Rejected at $0.01 \%$ significance 